\title{
INEQUALITIES IN STUDENTS' UNION LEADERSHIP: \\ THE ROLE OF SOCIAL NETWORKS
}

\begin{abstract}
Drawing on a national survey of students' union officers and staff, and a series of 24 focus groups involving both union officers and institutional senior managers, this article explores the characteristics of those who take up leadership roles in their (higher education) students' union. We show that, in several areas - and particularly in relation to gender, ethnicity and age - union leaders do not represent well the diversity of the wider student body. In explaining these inequalities, we argue that friendship groups and other peer networks play a significant role in determining who does and does not take up leadership positions. Moreover, as friendship groups are often formed on the basis of 'differential association' and are thus frequently socially homogenous, inequalities tend to be perpetuated. Wider institutional cultures and societal norms are also implicated.
\end{abstract}

Keywords: higher education, students' unions, friendship groups, social networks, diversity

\section{Introduction}

Within the UK, over recent years, students' unions have come to play an increasingly important role within higher education (HE) governance. Indeed, since the 1960s, the National Union of Students (NUS) (to which most institutional students' unions in the UK are affiliated) has been working to expand the role of unions in the governance of HE, and encouraging all universities to ensure student representation on decision making bodies 
(Rodgers et al., 2011). Students' union leaders are now typically members of many high-level institutional committees, and often have a close relationship with the vice-chancellor and/or other senior institutional leaders (Brooks et al., 2015). This has been brought about by a desire, on the part of higher education managers, to demonstrate that the 'student voice' is being taken seriously - which, in large part, can be related to the significant increase in tuition fees over recent years, and the increasing construction of the higher education student (within policy texts and amongst university managers, at least) as a consumer, whose demands need to be accommodated. Engaging with the students' union is also often seen as an effective means of gauging the views of the student body as a whole while, in a higher education sector in which more emphasis has come to be placed on 'the student experience' rather than just the process of teaching and learning, students' unions are often seen as important partners in the delivery of these wider aspects of university life (Sabri, 2012).

In this context, the characteristics of those who take on leadership positions within the students' union are significant: it seems important, from an equality perspective, that such positions of relative power are opened up to all students, and that the wider student body views their union leaders as broadly representative. Student leadership roles are also significant for society more generally as they often constitute, as Loader et al. (2014) have noted, the 'first significant rung on the ladder for professional recognition and future advancement' (p.1) for aspiring career politicians. Ensuring that all social groups have a fair chance of standing for such positions is thus crucial. While this paper draws on data from the UK only, its focus on the social characteristics of those who take up leadership positions in students' unions is likely to have broader resonance. Although, to date, little research has been conducted in this area, extant studies, from many countries, have highlighted differences in the nature of young people's political participation (by, for example, gender) (Vromen, 
2003), and there clearly remain significant inequalities in political leadership more generally across the globe.

The paper also articulates with research that has been conducted on processes of politicisation within university campuses more broadly. Despite allegations of political disengagement and apathy on the part of the young, the last five years have witnessed a considerable degree of political activity by young people, and much of it has been led by students - for example, protests against tuition fees, public funding cuts, and the privatisation of higher education, or as part of the Occupy movement (Sukarieh and Tannock, 2015). Such activity has been evident across the globe although, as Klemenčič (2014) notes, its impact has varied significantly, depending on wider cultural and political norms. Although the role of students' unions remains an under-researched area, within the UK at least, Crossley and Ibrahim (2012) have conducted important work on the relationship between students' unions and social networks within higher education institutions (HEIs). On the basis of their research in a UK university, they argue that campuses have a politicising effect on students, and unions play a key role in this process by helping to bring together like-minded individuals. They contend:

Dense [social] networks within halls of residence and courses may contribute but the network centralisation and focus provided by the Students Union is a more likely mechanism. Through their Union, by way of a poster advertising a meeting, politically inclined students can find one another and, assuming good relations are formed, generate the critical mass necessary to form political groups and mount political actions. (Crossley, 2008, p.29) 
They maintain that the union is both a focus for network formation and also a mechanism of resource mobilisation. In particular, they suggest that the union helps to provide a more collective environment for students than they are like to experience either pre- or postuniversity. Although they acknowledge that this need not necessarily lead to politicisation, they argue that 'it constitutes a facilitative resource (social capital) where politicisation is occurring' (Crossley, 2008, p.33). Furthermore, research from the US, UK and Australia has argued that smaller student societies, often facilitated by the students' union, are important loci for young people to develop their political habitus, providing space for the development and performance of the political self (Loader et al., 2014). Social networks are also significant in Hensby's (2013) analysis of processes of politicisation on campus. However, he suggests that some social networks (for example, of politically disengaged students) can serve to close down political activity and other types of involvement, instead of opening it up. Hensby describes these as 'counter networks' which, he contends, neuter students' desires to convert political interests into action. The current article engages with this emerging body of work by considering the impact of social networks on one particular type of political activity: recruitment into students' unions leadership positions.

\section{Methods}

The article draws upon data collected during 2012-13 as part of a project that sought to explore the nature of leadership within UK students' unions. The broader study was underpinned by a number of research questions about the roles played by students' union leaders, their perceived effectiveness and relationships between unions and their HEI (see Brooks et al. 2015 for further details). We were also interested in the characteristics and motivations of those who take up leadership positions, and data collected with respect to 
these issues form the basis of this article. Three main methods were used. First, an online survey was completed by students' unions officers across the UK. All the students' unions representatives on the NUS' database were contacted, by email, with information about the research, a request to complete the survey and a link to the relevant website. The email was sent to both elected officers (often called 'sabbatical officers' - because they are taking sabbatical leave from their studies to undertake these roles) and permanent students' union staff. Two reminder emails were sent, to maximise the response rate. The survey included both open and closed questions, and questions about the perceived diversity of students' union leadership and the social characteristics of respondents. 176 students' union officers completed the survey (from a sample of 400$)^{\mathrm{i}}$.

On the basis of an initial analysis of the survey data (using a range of descriptive statistics), ten higher education institutions were chosen to take part in the subsequent phase of the project, which aimed to generate more detailed, qualitative data through focus groups. This sub-sample was chosen to represent the diversity of the sector as well as different patterns of response to the questionnaire and comprised: three high status higher education institutions in the Russell Group ${ }^{\mathrm{ii}}$; two HEIs established in the 1960s, that are not part of the Russell Group; four newer institutions that gained university status after 1992; and one specialist HEI that offers a relatively limited range of courses ${ }^{\mathrm{iii}}$. In each institution, two focus groups were conducted: one with students' union officers (typically comprising four to six individuals), and a second with senior managers from the institution as a whole (typically comprising four individuals). In total, 88 people took part in one of the 20 focus groups: 42 senior managers and 46 students' union officers ${ }^{\text {iv }}$. The questions asked in the focus groups covered the research questions outlined above. In addition, we were concerned to compare the perspectives of staff and student leaders, to assess the extent to which they shared common 
views. Alongside the focus groups at the ten institutions, four additional focus groups were run to discuss, with student leaders, issues specifically related to the social characteristics of elected officers and students' motivations for standing for election. These focus groups were role-specific and comprised: presidents, education officers, welfare and community officers, and student activities officers ${ }^{\mathrm{v}}$. They were held during national training events for union officers, and so comprised union leaders from across the UK (from a wider range of institutions than those involved in the ten case studies). A total of 37 individuals were involved in one of these four groups.

All 24 of the focus groups were audio-recorded and fully transcribed. The transcriptions were subsequently uploaded to NVivo, for analysis. In the first stage of the analysis, the data were analysed by method of collection: descriptive statistics were generated for the survey data, and a thematic analysis was conducted on the interview transcripts. In the second stage of the analysis, data from all three stages were integrated; patterns were identified across the dataset as a whole, and theories and explanations developed. Analysis was informed by the project's research questions, but themes were also generated inductively from the data itself. In this paper, we draw primarily, although not exclusively, on the data from the institutional and role-specific focus groups.

\section{The diversity of UK students' unions}

In 2012, the Huffington Post worked collaboratively with the UK National Union of Students to ask candidates standing for election to national positions within the NUS a series of questions about how they intended to represent an increasingly diverse student population. This was prompted by concerns, initially raised by an existing member of the NUS national 
executive council, about the lack of representation for those not fitting the 'traditional' student mould. Indeed, the Huffington Post claimed that 'Traditionally, officers have been, unintentionally or not, biased towards only representing the needs of a certain type of students: undergraduates aged 18 to 25' (Sherriff, 2012, n.p). Such concerns have also been articulated, over the past decade, in various documents produced by the NUS itself (2010) as well as other stakeholders (e.g. ECU, 2007; Runnymede Trust, 2007).

Not all dimensions of diversity are, however, problematic. Indeed, the NUS' diversity report for 2009/10, which presented the findings of a national survey of the students' union workforce (elected officers and permanent members of staff), indicated that, in relation to both disability and sexual orientation, union officers represented well the diversity of the higher education sector (NUS, 2010). Fourteen per cent of union officers reported that they had a disability, health condition or impairment, compared with seven per cent of all higher education students; moreover, 10-11 per cent of respondents identified as lesbian, gay, bisexual or 'other', compared with six per cent of the population as a whole (NUS, 2010). Many of the qualitative responses to our own survey painted a similar picture, with respondents tending to think that their union leadership represented reasonably well the range of sexual orientations within the wider student body:

Over the past years we've had very good representation of LGBT+ officers on our sabbatical team, if anything it's higher than the proportion of LGBT students.

Four out of eight sabs [sabbatical officers] are LGBT...I doubt it's 50 per cent in the institution. 
The key areas of under-representation, identified by the NUS' survey, research conducted by the Equality Challenge Unit (2007) and our own study, are ethnicity, age and gender. In 2007, the ECU noted that, despite 20 per cent of NUS members being from black and minority ethnic (BME) groups, they accounted for fewer than four per cent of elected officers and sabbaticals (see also Runnymede Trust, 2007), and noted that those from BME backgrounds also faced barriers to entering students' union staff positions. By the time of the 2009/10 NUS survey, the percentage of BME officers had risen to 11 per cent, but this was still below BME representation across the sector as a whole at the time of the survey, which stood at 17 per cent (NUS, 2010). The qualitative comments from our research suggested that ethnic diversity remained a problem in 2012/13:

In [name of HEI] the sabs are always white, like it's always four white faces (Presidents' focus group)

Our whole sab team are white Caucasian and this does not completely accurately reflect the ethnic profile of our whole student body. (Survey respondent)

Our research also indicated that many participants did not consider their own student union leadership diverse in terms of age, either. Responses typically emphasised that it was rare for mature students to stand for election, and sabbatical officers tended to be drawn from the undergraduate, rather than postgraduate, population (which usually meant that their average age was lower). Again, a similar pattern was evident in the NUS' survey: 92 per cent of respondents were aged between 21 and 30, and none were 40 or older (NUS, 2010). With respect to gender, there is evidence of under-representation of women within students' union leadership teams generally and amongst those who are elected to the role of president, in 
particular (ECU, 2007; NUS, 2010). The NUS survey, for example, indicated that 47 per cent of union officer roles were held by women, although they comprised 57 per cent of the higher education population as a whole. Even more starkly, it reported that 72 per cent of presidents were men, and only 28 per cent women. Other roles are also significantly less likely to be held by women, including: treasurer/finance officer, clubs/societies officer, sports officer, and LGBT officer (ECU, 2007). Very similar patterns were revealed by our research in 2012-13, as the quotations below illustrate:

For the last, well for the last four years at least, there's only been one woman of the seven on the sab team. (Activities Officers' focus group)

At [my institution] women are more likely to run for like a welfare role and there's like a definitive thing where like women move to the welfare side and men run for the president side. (Presidents' focus group)

If it's president, ... I think a lot of people are, would look towards male people. And I think if it's welfare, potentially they look more towards female. (Welfare Officers' focus group)

In the remainder of this paper, we explore the reasons for this lack of diversity in some areas, considering both the social networks within which students are embedded and the wider institutional landscape. 


\section{Social networks and students' union leadership: a typology of students' groups}

In the following sections of this article, we draw on data from our own study, to focus specifically on social networks formed between students, and the extent to which there is evidence of the generation of facilitative social capital. A key aspect of the argument we develop is that social networks are, as Crossley and Ibrahim (2012) have contended, closely related to the ways in which students' unions function. However, while Crossley and Ibrahim argue that students' unions play a critical role in fostering social networks for students in general (by providing spaces for students to meet, facilities for them to use and structures for like-minded people to find one other), we suggest that this relationship often works in the other direction in relation to leadership positions specifically, i.e. that the nature and membership of social networks themselves have a significant bearing on who comes to take on a students' union leadership role. Moreover, while this often results in opportunities being opened up for 'traditional' students, it can serve to exclude those from less privileged backgrounds.

To discuss the functioning of different friendship groups and/or social networks within our sampled institutions, we describe below a three-fold typology of student groups: 'recruiting groups' (i.e. friendship groups that provided an important route into students' union leadership positions); 'disconnected groups' (i.e. friendship groups that were internally strong, but not well integrated into the wider university); and 'weak groups' (i.e. those that were much less strong, internally, and were also not well integrated institutionally). While this typology is only a heuristic device, and does not necessarily capture all the variation within our data, it does help to explain some of the ways in which student union leadership was socially differentiated. We acknowledge, however, the limitations of the evidence base 
we are drawing upon: while the first group is based on the first-hand accounts of those who fall into this group, the second and third groups are based on second-hand reports of those falling into first group, not first-hand accounts of uninvolved students.

\section{$\underline{\text { Recruiting groups }}$}

Many of the students' unions officers who took part in the research described how they, themselves, had been encouraged to stand for election by others in their friendship group or wider social network. Moreover, they explained how the encouragement of others had been critical in giving them the confidence to put themselves forward for a leadership position:

It was at the end of my second year when I was helping campaign for someone else and somebody said to me, 'This time next year we'll be writing your name on these signs', and I was like (laughs) 'Don't be ridiculous!' (others laugh). But it planted the seed .... it wasn't until that point that I realised. But then I suddenly realised, yeah, that makes sense, it just, it all slotted into place. (Activities Officers' focus group)

This quotation underlines the importance of the social networks within which students are embedded: here, encouragement was provided, very informally, by a network member, as part of an everyday exchange. Many other respondents described how they had also been encouraged to stand for election, and/or to become involved in the union in the first place, by a friend, or at least someone they knew from their wider social network in their institution. Indeed, within the Activities Officers' focus group, there was a sense that it was quite rare for students to run for office unless they had been encouraged by someone else, and often 
significantly harder for an individual to put themselves forward for election unless they were confident they had the support of others who had held a similar position:

Because when you look at an officer, how many of us here were approached by one of the officers and said you should run, rather than immediately think of it yourself? .... if you're encouraged by someone who is in that role to do it, you [feel] I can do this, it's fantastic, rather than just having to think of it yourself. (Activities Officers' focus group)

The significance of groups, rather than individuals, is also illustrated in the following quotation from the Presidents' focus group. Here, respondents are discussing ways in which the diversity of student leadership teams can be increased:

In our union, we don't do name titles, so I think the fact that it was the top five people that got the highest votes would be elected in, I think that took the pressure off going for a particular position headstrong. I think it takes away that fear and it opens it up to more groups that wouldn't necessarily see themselves as a leader straight away but then you get in and then you build the skills once you're in. So I think that makes a massive difference to our union. (Presidents' focus group)

The emphasis on opening union leadership up to 'more groups' is notable, and again highlights that, within many institutions, certain groups and/or friendship networks were seen as regular providers of student leaders, while others were seen as quite disengaged from union leadership. 
This reliance on friendship groups and other social networks as a common mechanism for recruiting student leaders goes some way to explain the relative lack of diversity of union leadership in some of the areas discussed in the earlier part of the paper. Indeed, a considerable body of research has documented the homogeneity of friendship groups within educational institutions (Papapolydorou, 2014; Reay et al., 2007). In common with studies of friendship more generally, it is argued that friendships marked by significant social difference are hard to maintain, because it is difficult to manage status inequality between friends (Allan, 1998). Within the higher education sector, studies have evidenced how friendship groups are often delineated along class lines, with those from working-class and middle-class backgrounds often remaining distant from one other. Keane (2011), for example, has shown how, in her research in an Irish higher education institution, the non-traditional students were aware that they did not have access to the same economic or cultural resources as their middle-class counterparts. They were thus worried about being rejected as interlopers and, as a consequence, 'refused to engage in friendship-building with "other" students' (p.455). For these students, Keane concludes, feeling subserviently positioned was a common experience. Similar findings have emerged from US studies, which have pointed to the homogeneity of friendship groups on campus. Aries and Seider (2005), for example, have argued that many of the lower income students in their research 'felt their class backgrounds made it difficult for them to connect to the wealthy students' (p.428), and frequently expressed feelings of inadequacy, inferiority and intimidation.

Friendship groups tend also to reflect other axes of social difference. Hollingworth and Mansaray (2012) have demonstrated how, even within a diverse, metropolitan sixth form, in which 'social mixing' was officially celebrated by both staff and students, patterns of friendship were strongly inflected by ethnic difference, and the spaces of the school were 
'raced'. Similarly, within higher education, there is evidence of the dominance of sameethnic friendships (Reynolds, 2007). Ball et al. (2002) have argued that some BME students, particularly those from families without a previous history of higher education, pay close attention to the ethnic mix of institutions when deciding where to apply. Indeed, they contend that 'choice was for some students, in part, about sustaining aspect of their ethnic identity or having this identity valued and defended, or at least not having to defend or assert the value of their identity' (p.348); institutions where difference and diversity were perceived as 'normal' were particularly valued. Moreover, as Reynolds (2007) notes, universities also offer 'the space, opportunity and networking possibilities for black students [the focus of her research] to meet and socialise with other black students and further explore issues of ethnic and racial identity through their participation in ethnic specific events' (p.392).

With respect to international students, although there is evidence that some groups are able to penetrate the friendship groups of 'home' students, this does not seem to occur across the board. Indeed, Rienties et al.'s (2014) longitudinal study of the social integration of international students in the UK has shown how Confucian Asian students, in particular, often continue to live in separate social worlds throughout their degree programmes. This replicates other studies, across the globe, which have indicated that international students often mix well with other international students, but not necessarily with the local population (Fincher and Shaw, 2009; Waters and Brooks, 2011). Thus, there is strong evidence that, within educational institutions, as in other contexts, processes of 'differential association' (Bottero, 2005) occur: people do not associate with others randomly, or on the basis on arbitrary personal preference. Instead, association tends to be with those who hold similar social resources. If recruitment to student leadership positions is primarily through social networks and the encouragement of friends, then it is perhaps unsurprising, given the 
evidence about the homogeneity of friendship groups, that the social characteristics of student leaders are not more diverse.

\section{Disconnected groups}

In the examples from our data provided above, we demonstrated how some friendship groups and social networks played a significant role in 'feeding through' students to stand for leadership positions. It is our contention, however, that friendship groups can also exert influence in the opposite direction, by their positioning as disconnected from students' union leaders and/or the students' union in general. In some ways, these can be seen as akin to the ‘counter networks' described by Hensby (2013), which may act to deter political participation.

The friendship groups of international students, for example, were often spoken about as internally strong, but disconnected from students' union leaders. Some respondents explained this disconnection by pointing to the lack of role models available to such groups. Indeed, one participant in the focus group for Activities Officers described how, at her HEI, although there was a very large number of international students from China, none ever ran for any of the sabbatical positions. She believed that they were deterred, largely, by the lack of any role models from within the union: 'They look at the history of the union and then like they just never have done in the past, so they haven't got any sort of reference point to, say oh this guy/girl ran for it and they succeeded.' Moreover, several respondents noted that while some international student societies were strong groups within the institution, they rarely fed through any candidates for union leadership elections. For example, a participant in the Presidents' focus group claimed that while their institution had many vibrant international 
student societies, 'they stick to their own sort of cliques and there is no sort of integration with the rest'. Again, we can see evidence of 'differential association' (Bottero, 2005). It may also be the case that some groups see greater benefit from remaining within their own friendship/social groups than interacting with a more diverse group of students. For example, in discussing the relative lack of social integration of Confucian Asian students, Rienties et al. (2014) suggest that:

while it may be true that they may not benefit from a wider network, they may reap potential benefits from building social capital among those within the same culture. For instance, building interpersonal relationship within Chinese culture is often noted to be particularly important in one's personal and professional success .... Thus, it could be argued that social capital is also enhanced through this practice of social networking within the same culture, which may benefit the students in the present and in the future. (p.19)

Our data suggest that policies promoted by the students' union, itself, may also - in some institutions - be exacerbating the marginal place of some groups. For example, a number of respondents described how their students' union had recently changed its policy to allow officers to stand for re-election, and thus occupy a specific leadership position for two years rather than one. This was usually justified on the grounds that it made it easier for the union to pursue a more coherent strategy, and often increased their effectiveness as re-elected officers already knew well the institution and key institutional contacts. However, others expressed concern that this policy made it harder for unions to recruit a diverse leadership team: 
I think it's critically important that people have the opportunity to get involved from the outside, that it does, that we really support and really try very hard to get people that are not part of the culture of the student union to keep feeding the same engine, that we do have the fresh insight and that you promote that in a very active way. And one of the ways is of course not allowing a sabbatical officer more than one year, that certainly helps with not keeping people in power or you know in these roles and get kind of institutionalised within student union. (Education Officers' focus group)

Nevertheless, our research indicates that allowing re-election has become more common and, in many institutions, is supported by both students' unions and senior HEI management. While such a change may produce stronger, more confident student leaders, who feel they have more time to develop and implement their policies, it may also reduce the diversity of the 'student voice' and make it harder for those from under-represented groups to gain power.

\section{'Weak groups'}

A third and final group of students were connected to much looser social networks, or what we have called 'weak groups' in our typology. Often these were students who, for various reasons, were unable to spend significant amounts of time on campus - particularly outside their studies - and thus had fewer opportunities to: establish strong bonds with many other students; integrate fully into strong friendship groups; and/or make links to those already involved with the students' union. The imperative for some students, particularly those from low income families, to undertake paid employment alongside their studies often left little time for such pursuits. One students' union president explained that, although he did ultimately stand for election, he believed it was more difficult for him than for his peers who 
did not need to engage in paid work, and that this was a significant barrier for those from less privileged backgrounds:

And I don't think it's a thing that like people are like, oh yeah, we're not voting for this person because they're working class, I think there's like more practical barriers. So like during my time at university, I have to work part time quite a lot, so I couldn't get involved with societies and make like big meetings or run for executive committee positions because I just didn't have the time in the week. And I think that's where the kind of class thing is a barrier....you're just at a disadvantage against people who didn't have to work during their studies, didn't have to work that much.

Those who live in the parental home throughout their degree, in order to save money, may face similar barriers to becoming involved in extra-curricular activities (Crossley, 2008). This was discussed explicitly by a number of our respondents who believed that communal forms of student accommodation, either in halls of residence or shared student houses, were important in 'spreading the word' about the union, and enabling those with some connection to the union to intersect a larger number of social networks, and encourage others to become involved. Indeed, at one of our case study institutions, the absence of halls of residence for any student, as a consequence of the institution's inner city location, was thought by union officers who took part in the focus group to have had a significant (negative) impact on knowledge of and participation within the students' union: 'if none of your friends are in the SU [students' union], you've never talked about the SU, you're not, I don't think you're as likely to engage with it'. 
Respondents in our study also discussed the difficulty, for many of their fellow students with childcare commitments, of returning to campus for union events (and other activities) held in the evenings. While unions can clearly respond to these situations in constructive ways - for example, by scheduling meetings during the day and/or making greater use of online fora the enduring importance of social networks for facilitating union involvement and leader recruitment acts as a barrier for those who find it hard to be physically present. Moreover, as the wider literature on students with caring responsibilities has shown, sometimes institutional policies and practices, such as prohibitions on bringing children onto campus and the scheduling of social events in the evenings and at weekends (Marandet and Wainwright, 2010), can make it harder for such students to socialise on campus, and thus establish strong friendship groups.

In most cases, those who find it hard to be physically present are those from 'non-traditional' and typically under-represented groups. As we have noted above, these include students from less economically advantaged families, who need to take up paid employment to be able to afford their higher education studies and/or may choose to live in the parental home to reduce both the social and economic risks of higher education, and mature students who are often subject to the same financial constraints and of whom a considerable proportion have caring responsibilities. While in Reay et al.'s (2001) research on HE choice, the mature students in their sample exhibited more collectivist behaviours than their younger counterparts (for example, providing support to one another as they made their decisions about where to apply for university), research within higher education suggests that, outside formal lectures and seminars, mature students often face particular barriers that make further social engagement difficult. They are less likely to receive support and encouragement from peers (via 
friendship groups) to stand for election (or indeed become involved in the union in the first place), and also less likely to have the time to commit to such pursuits.

\section{Social networks and the wider institutional landscape}

When considering the role of social networks, it is important to situate them within the context of the wider institutional landscape. This can help to explain the relative social positioning of groups, but also patterns of recruitment into leadership positions that cannot be explained solely on the basis of social networks.

Indeed, in explaining why some socially-homogeneous groups provided candidates for union leadership positions and others did not, it is notable that those groups that routinely fedthrough members for election tended to occupy a more central position within the wider HEI than others. Extant research has highlighted the way in which university campuses are not experienced in identical ways by all social groups (or indeed by all friendship groups, given the way in which many friendship groups are differentially associated). For example, as noted above, the lack of integration of international students has been documented across the HE sector at large, although research has typically suggested that social segregation is rarely a direct result of international students 'sticking to their own clique' (as suggested by the Presidents' focus group above) but a product of more structural factors at play that militate against integration (Madge et al., 2009). Moreover, university campuses are often experienced as middle-class institutions that are not necessarily welcoming of the working-

class habitus (Archer et al., 2003), and/or as exclusionary and hostile spaces by students from particular ethnic and/or religious backgrounds. Hopkins (2011) has argued, in the HEI in which he conducted research, the dominance of a drinking culture, the lack of halal food, and 
the particular location of the campus mosque 'point to the influence of institutional discrimination and everyday marginalisation in determining the provision of student facilities and students' experiences of campus geographies' (p.163-4), with Muslim students, in particular, feeling excluded.

Such norms also help to account for patterns of recruitment into leadership positions that cannot be explained solely on the basis of social networks. This is particularly relevant in relation to the position of women who may be expected to be represented within many types of friendship group across campus, and yet are notably under-represented within the leadership of students' unions. Extant research has suggested that although women now constitute over half of the UK student population, HEI cultures have not always undergone a similar degree of change. For example, Leathwood and Read (2009) argue that although new forms of student identity are being produced as the HE sector changes, these identities (which they categorise as 'independent learner', 'needy student', student as consumer and 'future graduate') are easier to take on for men than for women, as they are all consonant with dominant constructions of masculinity. Moreover, other research has suggested that new forms of sexism are becoming rife on many campuses, linked to the emergence of a 'lad culture' (Phipps and Young, 2014). Developing a similar analysis, Andersson et al. (2012) argue that while, in theory, university campuses offer the potential for cross-cultural contact and mutual learning, in practice 'the narratives of encounter produced within the campus context frequently reflect the positions of those who are particularly privileged as campus "insiders"” (p.512). These insiders, they contend, are typically white, middle-class, secular and male. Indeed, they suggest that women are objectified by the dominant commercial culture that operates on many UK campuses (played out through nightclubs, beauty salons, hairdressers etc.) and thus "while the "official" rhetoric of the university supports values of 
gender equality...the actual experience of the commodified campus can blatantly contradict this ethos' (p.505). 'Outsiders' may also include students from black and minority ethnic groups who are, for example, less likely to secure a first or upper second class degree than their white counterparts (Equality Challenge Unit, 2013), and mature students and/or those with dependent children, and some groups of international students, who often face particular barriers (Brooks, 2012; Madge et al., 2009). Indeed, as the Activities Officers' focus group stated: 'I think a lot of the reasons why we might have issues, whether gender, with international students, BME, whatever, I think it is rooted quite deeply in the cultural issues within the university itself'. International and BME students are perhaps more likely than women to form socially homogenous friendship groups but, irrespective of their social networks, their 'outsider status' may make recruitment to student union leadership positions less likely.

Such institutional norms are clearly not divorced from those of wider society. Indeed, both women and those from ethnic minority backgrounds are under-represented within the UK parliament and current government (Annesley and Gains, 2012; Durose et al., 2013), and in many other areas of public life, such as on company boards (e.g. Sealy and Vinnicombe, 2013). Our data suggest that such norms affect students' conceptions of 'typical leaders'; for example, a participant in the Welfare Officers focus groups stated: 'I've found that, you know, some of the male students wouldn't take a female candidate seriously, be like oh why is a girl running for president or anything'. Here, there is resonance with research within the further education sector, which has suggested that, within students' unions, men are more likely than women to assume leadership roles (Brooks, 2009), while Roker and Eden's (2002) research on youth participation more generally indicated that although more females than males took part in 'social action' projects, young men were more heavily involved in 
leadership roles in youth councils which, they argue, had a more 'masculine' image. These studies support the thesis that women's skills and aptitudes are often 'misrecognised' through (usually unintentional) gender bias (Morley, 2013).

However, as the data above demonstrate, traditional patterns of inequality do not seem to be being reproduced in any necessarily straightforward manner. In particular, our data suggest that LGBT students were well represented in students' union leadership positions. This may be explained by the significant decline in homophobia amongst student groups over recent years (McCormack, 2012). It may also be related to the position of LGBT student societies on campus, which have, in many universities in the UK, secured a relatively large membership and played an active role in politicising issues related to sexuality. As students' unions have often facilitated such political activity, standing for a leadership position within the union may seem a much less daunting proposition for those who have been closely involved in a LGBT group than for other students. While this is just a possible explanation for the patterns observed, it does articulate with the work of those who have argued that student societies can play a key role in inculcating the necessary social and cultural capital to enable young people to take on positions of political influence (Loader et al., 2014).

\section{Conclusion}

Like previous studies, our research has revealed the narrowness of students' union leadership teams in the UK in a number of important dimensions. However, it has extended this work by offering some explanations for these patterns, drawn from focus groups with union officers and senior institutional managers. We have argued that friendship groups and wider social networks play a key role in influencing who does or does not put themselves forward for 
election. While some groups act as 'recruiters' to student leadership positions, others exert influence in the opposite direction, largely because of the way they are positioned within the wider institution. Our conclusions thus resonate with those of others who have argued that higher education should be seen as an embedded social practice, in which networks of friends and family exert strong influence on the decisions individuals make about their HE destinations (Heath et al., 2010). They also serve to underline the importance of social networks once students have arrived at their higher education institution. Despite the competitive nature of peer relations within some HE classrooms, friends remain important for many students throughout their degree programmes, providing social support, resources for identity-building and establishing a sense of belonging, and opportunities for informal learning (Wilcox et al., 2005).

Our focus on social networks also complements the work of others who have explored processes of politicisation on campus. However, while evidence suggests that social networks and student societies can have an important and positive impact on the politicisation of students, in general (Crossley and Ibrahim, 2012; Loader et al., 2014), our data indicate that with respect to students' union leadership positions specifically, the impact of friendship groups and other social networks is more complex. While some groups played an active 'recruiting' role, others appeared 'disconnected', or were weakly associated with the HEI as a whole, and thus made involvement in the union less likely. In developing our argument, we have suggested that social composition of these different types of group is linked closely to well-documented inequalities across the HE sector as a whole. For example, non-traditional students were less likely to be found in the 'recruiting' groups than their more privileged peers. Nevertheless, our research also indicates that the composition of students' union leadership teams cannot be simply 'read off' broader societal inequalities. LGBT students, in 
particular, were well-represented among the leaders of the students' unions involved in the study, and provide an intriguing example of how - in some cases - societal norms can be challenged effectively on campus. As students' unions are brought closer into institutional governance structures, it is important that such challenges are sustained.

\section{Acknowledgements}

We are grateful to the National Union of Students and the Leadership Foundation for Higher Education for funding the project upon which this paper is based, and all the respondents who kindly gave up their time to take part. We would also like to thank the anonymous referees whose extremely helpful comments strengthened the paper.

\section{References}

Allan, G. (1998) Friendship, sociology and the social structure, Journal of Social and Personal Relationships, 15, 5, 685-702.

Andersson, J., Sadgrove, J. and Valentine, G. (2012) Consuming campus: geographies of encounter at a British university, Social and Cultural Geography, 13, 5, 501-515.

Annesley, C. and Gains, F. (2013) David Cameron's 'problem' with women: representing women in the Coalition government, The Political Quarterly, 83, 4, 718-725.

Archer, L., Hutchings, M. and Ross, A. (2003) Higher Education and Social Class London, Routledge. 
Aries, E and Seider, M (2005) The interactive relationship between class identity and the college experience: the case of lower income students, Qualitative Sociology, 28, 4, 419-443.

Ball, S., Reay, D. and David, M. (2002) 'Ethnic choosing': minority ethnic students, social class and higher education choice, Race, Ethnicity and Education, 5, 4, 333-357.

Bottero, W. (2005) Stratification: Social Division and Inequality London, Routledge.

Brooks, R. (2009) Young People and UK Citizenship Education: a gender analysis, Young, $17,3,307-326$.

Brooks, R. (2012) Student-parents and higher education: a cross-national comparison, Journal of Education Policy 27, 3, 423-437.

Brooks, R., Byford, K. and Sela, K. (2015) The changing role of students' unions within contemporary higher education, Journal of Education Policy, 30, 2, 165-181.

Crossley, N. (2008) Social networks and student activism: on the politicising effect of campus connections, The Sociological Review, 56, 1, 18-38.

Crossley, N. and Ibrahim, J. (2012) Critical mass, social networks and collective action: exploring student political worlds, Sociology, 46, 4, 596-612. 
Durose, C., Richardson, L., Combs, R., Eason, C. and Gains, F. (2012) ‘Acceptable difference': diversity, representation and pathways to UK politics, Parliamentary Affairs, 66, 2, 246-267.

Equality Challenge Unit (ECU) (2007) Inclusive Students' Unions: Survey Findings 2007 London, ECU.

Equality Challenge Unit (ECU) (2013) Equality in Higher Education: Statistical Report 2013 Part 1: Students London, Equality Challenge Unit.

Fincher, R. and Shaw, K. (2009) The unintended segregation of transnational students in central Melbourne, Environment and Planning A, 41, 1884-1902.

Heath, S., Fuller, A. and Johnston, B. (2010) Young people, social capital and network-based decision-making, British Journal of Sociology of Education, 31, 4, 395-411.

Hensby, A. (2013) Networks, counter-networks and political socialisation - paths and barriers to high-cost/risk activism in the 2010/11 student protests against fees and cuts, Contemporary Social Science, 9, 1, 92-105.

Hollingworth, S. and Mansaray, A. (2012) Conviviality under the cosmopolitan canopy? Social mixing and friendships in an urban secondary school, Sociological Research Online, 17,3 . 
Hopkins, P. (2011) Towards critical geographies of the university campus: understanding the contest experiences of Muslim students, Transactions of the Institute of British Geographers, $36,157-169$.

Keane, E. (2011) Distancing to self-protect: the perpetuation of inequality in higher education through socio-relational dis/engagement, British Journal of Sociology of Education, 32, 3, 449-466.

Klemenčič, M. (2014) Student power in a global perspective and contemporary trends in student organising, Studies in Higher Education, 39, 3, 396-411.

Leathwood, C. and Read, B. (2009) Gender and the changing face of higher education: a feminized future? Maidenhead, Open University Press.

Loader, B., Vromen, A., Xenos, M., Steel, H. and Burgum, S. (2014) Campus politics, student societies and social media, The Sociological Review. (Advance online access)

Madge, C., Raghuram, P., and Noxolo, P. (2009) Engaged pedagogy and responsibility: a postcolonial analysis of international students, Geoforum, 40, 34-45.

Marandet, E. and Wainwright, E. (2010) Invisible experiences: understanding the choices and needs of university students with dependent children, British Educational Research Journal, $36,5,787-805$. 
McCormack, M. (2012) The Declining Significance of Homophobia, Oxford, Oxford University Press.

Morley, L. (2013) Women and Higher Education Leadership: Absences and Aspirations London, The Leadership Foundation for Higher Education.

National Union of Students (NUS) (2010) Diversity Survey Report 2009/10 London, NUS.

Papapolydorou, M. (2014) 'When you see a normal person...': social class and friendship networks among teenage students, British Journal of Sociology of Education, 35, 4, 559-577.

Phipps, A. and Young, I. (2014) Neoliberalisations and 'lad cultures' in higher education, Sociology (Advance online access).

Reay, D., David, M. and Ball, S. (2001) 'Making a difference?' Institutional habituses and higher education choice, Sociological Research Online, 5, 4.

Reay, D., Hollingworth, S., Williams, K., Crozier, G., Jamieson, F., James, D. (2007). A Darker Shade of Pale?: Whiteness, the middle classes and multi-ethnic inner city schooling Sociology, 41, 6, 1041-1060.

Reynolds, T. (2007) Friendship networks, social capital and ethnic identity: researching the perspectives of Caribbean young people in Britain, Journal of Youth Studies, 10, 4, 383-398. 
Rienties, B., Johan, N. and Jindal-Snape, D. (2014) A dynamic analysis of social capitalbuilding of international and UK students, British Journal of Sociology of Education (Advance online access).

Rodgers, T, Freeman, R., Williams, J. and Kane, D. (2011) Students and the governance of higher education: a UK perspective, Tertiary Education and Management, 17, 3, 247-260.

Roker, D. and Eden, K. (2002) A Longitudinal Study of Young People's Involvement in Social Action: the Youth and Social Action Project (Brighton, Trust for the Study of Adolescence).

Runnymede Trust (2007) Not Enough Understanding? - Student Experiences of Diversity in UK Universities Runnymede Trust, London.

Sabri, D. (2012) What's wrong with the 'student experience'? Discourse: Studies in the Cultural Politics of Education, 32, 5, 657-676.

Sealy, R. and Vinnicombe, S. (2013) The Female FTSE Board Report 2013: False Dawn of Progress for Women on Boards? International Centre for Women Leaders at the Cranfield School of Management.

Sherriff, L (2012) NUS officer elections 2012: How will candidates represent the diverse student population? The Huffington Post UK Available online at: http://www.huffingtonpost.co.uk/2012/04/23/nus-elections-2012-candidates-representingdiverse-students_n_1445373.html (Accessed 17/11/14). 
Sukarieh, M. and Tannock, S. (2015) Youth Rising? The Politics of Youth in the Global

Economy New York, Routledge.

Vromen, A. (2003). "People try to put us down." Participatory citizenship of 'Generation X'.

Australian Journal of Political Science, 38(1), 79-99.

Wilcox, P., Winn, S. and Fyvie Gauld, M. (2005) 'It was nothing to do with the university, it was just the people': the role of social support in the first-year experience of higher education, Studies in Higher Education, 30, 6, 707-722.

Waters, J. and Brooks, R. (2011) 'Vive la différence'? The 'international' experiences of UK students overseas. Population, Space and Place, 17, 5, 567-578.

\footnotetext{
${ }^{i}$ We note that there may well be some bias in the responses. For example, those who chose to complete the survey may have had stronger views about the issues covered than those who did not complete it. Nevertheless, the survey responses cover a wide variety of views and, with respect to the reported social characteristics of students' union leaders, are broadly in line with the findings of other research.

ii The Russell Group is comprised of 24 'research intensive' HEIs, which typically occupy high positions in national league tables.

iii Institutions in neither of the final two categories are part of the Russell Group.

iv No data were collected about the political orientation of the students' unions leaders. We thus do not have any robust evidence about the relationship between the political orientation of unions and their inclusiveness. However, the patterns discussed in this article were common across a large number of unions, which would suggest that political orientation may have a relatively limited effect.

${ }^{v}$ Education officers oversee matters related to teaching and learning; welfare officers typically offer support to individual students on any welfare matter, and lead their union's work on welfare and student rights; and activities officers hold responsibility for student societies (including, in some cases, sports clubs).
} 